\title{
Dysthyroid optic neuropathy: update on pathogenesis, diagnosis, and management
}

\author{
Alexander D. Blandford, MD', Dalia Zhang ${ }^{2}$, Rao V. Chundury, MD, MBA ${ }^{3}$, and Julian D. \\ Perry, MD ${ }^{1}$ \\ ${ }^{1}$ Cole Eye Institute, Cleveland Clinic Foundation, 9500 Euclid Avenue, Cleveland, OH 44195 \\ ${ }^{2}$ Case Western Reserve University School of Medicine, 2109 Adelbert Road, Cleveland, $\mathrm{OH}$ \\ 44106
}

${ }^{3}$ Eugene and Marilyn Glick Eye Institute, Indiana University, 1160 W Michigan St, Indianapolis, IN 46202

\begin{abstract}
Introduction-Dysthyroid optic neuropathy (DON) is a severe manifestation of thyroid eye disease (TED) that can result in permanent vision loss. Management is complex, multidisciplinary, and involves medical and/or surgical therapies. This review describes current concepts in the epidemiology, pathophysiology, diagnosis, and treatment of DON.
\end{abstract}

Areas covered-An extensive review of the literature was performed to detail current concepts on the diagnosis and management of DON. This includes utilization of various medical and surgical modalities for disease management.

Expert commentary-DON can result in permanent blindness and often requires the use of corticosteroids and surgical decompression. We favor the use of intravenous corticosteroids and a transcaruncular approach when surgical decompression is indicated. The use of orbital radiation for DON is often reserved for patients that are poor surgical candidates and/or patients with refractory disease.

\section{Keywords}

Graves' Ophthalmopathy; Thyroid Eye Disease; Dysthyroid Optic Neuropathy; Compressive Optic Neuropathy; Orbital Apex Syndrome; Orbital Decompression; Orbital Radiotherapy; Rituximab

\section{Introduction}

Thyroid eye disease (TED) represents the most common extraocular manifestation of Graves' disease (GD). While the pathophysiology behind Graves' hyperthyroidism is fairly well understood, that of Graves' orbitopathy is less so. Approximately $50 \%$ of patients with

\footnotetext{
Declaration of interest

The authors have no relevant affiliations or financial involvement with any organization or entity with a financial interest in or financial conflict with the subject matter or materials discussed in the manuscript. This includes employment, consultancies, honoraria, stock ownership or options, expert testimony, grants or patents received or pending, or royalties.
} 
GD will suffer from TED before, during, or after the development of hyperthyroidism. While about 60 percent only experience mild discomfort related to eyelid retraction, some $35 \%$ will suffer from diplopia interfering with daily life activities or disfiguring proptosis, and finally 3-7\% develop vision threatening complications such as dysthyroid optic neuropathy (DON)[1]. This review provides a consolidated overview of our current understanding of DON.

\section{Overview and Epidemiology}

The overall prevalence of GD is 13.9 per 100,000 in the United States, with no significant ethnic predisposition[2]. Approximately $25-50 \%$ of these patients will display clinically apparent ophthalmopathy, though imaging reveals subclinical features in the majority[2,3]. The gender distribution of patients with TED shows a 5:1 predominance of females over males, yet patients with severe eye disease are more likely to be male and over age 60 years $[1,2,4,5]$.

The natural history of TED is characterized by an active inflammatory phase lasting about 1-3 years and followed by an inactive fibrotic phase [6]. About $1 \%$ of patients experience recurrence of active disease, sometimes years following remission. While the majority of patients who develop TED exhibit mild-to-moderate symptoms that require only supportive treatments, about 3-7\% experience severe inflammation resulting in sight-threatening ophthalmopathy from exposure keratopathy or DON[2]. (FIGURE 1)

\section{Risk Factors}

Several genes related to immune modulation, thyroid hormone metabolism and other mechanisms have been implicated in the pathogenesis of TED, however none has been found to be necessary, sufficient, or specific to the development of TED and/or DON[3]. Numerous other risk factors are associated with TED including age, gender, genetics, smoking, thyroid dysfunction, as well as treatments for hyperthyroidism. Discordant identical twin studies suggest that both genetic and environmental factors[7]. Some of these risk factors may also be associated with the development of DON.

The prevalence of smokers in patients with TED is markedly high relative to all other thyroid disorders[8]. Tobacco use is associated with a $7-8 \times$ increased risk for developing TED, increased disease severity, and a dampened response to treatment $[9,10]$. Smoking may represent a risk factor for DON as well, although the evidence is not as overwhelming. A recent review of 604 patients with Grave's orbitopathy found an odds ratio (OR) of 1.5 for current smokers developing DON, but this was not statistically significant[11]. Wiersinga et al identified male sex, older age, and heavy smoking as the biggest risk factors for developing DON, however no detailed statistics were provided[12]. Another retrospective study found smoking to be the strongest predictive factor in the development of both severe TED $(\mathrm{OR}=6.57)$ and $\mathrm{DON}(\mathrm{OR}=10.00)[13]$.

Diabetes mellitus (DM) has also been cited as a risk factor for TED. There exists a complex interplay between glycemic control and thyroid function. While the prevalence of diabetic patients with TED is similar to the normal population $(0.22-0.26 \%)$, the prevalence of 
patients with insulin-dependent diabetes mellitus (IDDM) is significantly higher (1.7\%), and among these patients, the disease course is generally more severe and refractory [14]. The vasculopathy associated with DM leads to marginal oxygenation of the optic nerve, leaving it more susceptible to damage due to EOM expansion and optic nerve compression. In one study, while only $3.1 \%$ of patients with TED had diabetes and 3.9\% developed DON, 33.3\% of patients with diabetes eventually developed DON. Medical and/or surgical treatment may be less effective in improving visual outcome for patients with diabetes[15].

Thyroid dysfunction is closely related to the development and severity of TED. Dysthyroidism has long been observed to contribute to the development and progression of TED; potential risk cofactors include hypothyroidism as well as the severity, duration, and recent onset of hyperthyroidism. Establishment and maintenance of euthyroidism is essential[16]. The specific treatment of thyroid dysfunction may impact the course of TED[16]. Radioiodine (RAI) therapy may increase the risk of TED progression by 15-39\% over anti-thyroid medications or thyroidectomy[3]. In the same way, RAI may increase the risk of developing DON, although no meaningful data exist to validate this extrapolation.

Age and gender also appear to influence the severity of TED, including the development of DON. Increased age correlates with greater severity of thyroid eye disease and age may represent one of the biggest risk factors for DON[2,5]. Patients with DON are significantly older than those with TED alone, with an average age of 61 years[4]. In another large retrospective study, $8.6 \%$ of patients with TED developed DON, and patients with DON were older (54 years versus 46 years)) compared to those without DON[1]. Several other studies also show a strong correlation between age and DON $[17,18]$. For every decade increase in age of onset of TED, the odds of developing DON may increase by 58\%[11]. Age may also affect the response to DON treatment with younger age predicting a better outcome ( $\mathrm{p}=0.049)[19]$. Male gender also shows a strong correlation with the development of DON, especially with advancing age[1,4,5,17].

\section{Pathophysiology}

The pathogenesis of DON has been described as having mechanical, vascular, and inflammatory components. The most widely accepted mechanism is secondary to an apex or compartment syndrome from orbital fibroblast deposition of hyaluronic acid (HA) leading to extraocular muscle (EOM) enlargement, enlargement of orbital fat, and overall increased vascular congestion[1,20-25].

As the EOMs converge at the orbital apex, their common insertions form the annulus of Zinn. Here, the medial rectus is most proximal to the optic nerve and compression from EOM swelling can cause optic nerve ischemia or inhibit axonal flow. The medial rectus volume, which can be approximated by medial rectus axial diameter, seems to be the strongest predictor of DON[26]. Orbital computed tomography (CT) studies demonstrate significant optic nerve crowding at the orbital apex in the vast majority of patients with DON, and may also demonstrate intracranial fat prolapse or an increased superior ophthalmic vein diameter[1,23,27,28]. Also implicating direct optic nerve compression in DON is that retrobulbar pressure markedly decreases after decompression surgery[29]. 
Orbital fibroblasts represent the main effector cells in TED; in addition to producing HA to cause congestion and compression, fibroblasts may differentiate and proliferate[11]. The TSH receptor serves as the autoimmune target in TED and antibody levels correlate with disease activity and severity. Orbital fibroblasts in TED, as compared to normal individuals, express higher levels of TSH receptor, suggesting its potential role as an autoantigen[30]. Insulin-like growth factor-1 receptor (IGF-1R) appears to activate orbital fibroblasts to cause cell proliferation, adipogenesis, and HA synthesis[30]. A subset of fibroblasts may arise from fibrocytes, which are CD34+ mesenchymal cells derived from bone marrow. These circulate as mononuclear cells capable of infiltrating tissue to participate in inflammation, healing, and fibrosis. This leads to fibrotic, less compliant muscles in the apex, which may contribute to the development of DON[20]. (FIGURE 2)

In addition to apex compression and inflammation, changes in orbital vasculature may relate to DON. Doppler sonography shows the superior ophthalmic vein as the most susceptible to changes, exhibiting decreased flow in the active stage and reversed or absent flow in the setting of severe orbitopathy[31]. These vascular changes may contribute to DON. Rarely, short optic nerve or stretch of the optic nerve may cause DON in the absence of EOM involvement[32]. The mechanism by which this occurs may involve the optic nerve vasculature to produce ischemia.

\section{Clinical presentation and diagnosis}

Multiple objective measures grade the physical signs, symptoms, and severity of TED, including NO SPECS, CAS, VISA, and EUGOGO (Table 1 and 2) however, no single protocol completely characterizes DON [33-36]. Patients may be classified as Type I or Type II, with predominantly fat or EOM enlargement, respectively [37]. Type II orbitopathy may more commonly produce DON, as patients with a muscle index $<50 \%$ rarely develop DON[21,23,28]. Further, retrobulbar fat volume compares similarly in TED patients with or without DON. Alternatively, Type I and Type II classifications may simply represent extremes on the sprectrum of disease presentation; results from a large tertiary referral center found that the majority of patients presenting with TED demonstrated predominantly an increase of their orbital muscle volume[38].

Most clinicians utilize a combination of clinical and radiological findings to diagnose DON. Tissue enlargement in patients with DON often results in congestion at the orbital apex rather than severe proptosis, and patients may not demonstrate external signs of overt orbital inflammation[25]. The visual acuity often lags behind other symptoms and signs of DON. Color vision, pupillary exam, contrast sensitivity, and automated visual field perimetry help characterize optic nerve function for the diagnosis and management of DON, and DON may result in some characteristic changes in these tests. (FIGURE 3)

Visual acuity decline in TED often occurs from etiologies other than DON, including tear film abnormalities, poor blink, exposure, and resultant corneal irregularities[23]. While decreased acuity is nonspecific, it is decreased more in eyes with DON compared to those with TED alone. In one study, only 53\% of patients with DON had visual acuity of 20/40 or better, compared to $97 \%$ of patients having TED without DON[1]. 
An afferent pupillary defect in the setting of TED is highly specific for DON[1]. However, it may be absent in bilateral DON, or it may occur for reasons other than DON. Color vision changes represent an early sign of optic nerve compression. Contrast sensitivity may diminish in TED patients who do not show other signs of DON, indicating this test may detect subclinical optic nerve damage early in the disease process[39].

Visual field testing accurately detects DON[14]. Nearly all eyes with DON develop a central or paracentral scotoma, and many develop other peripheral breakout patterns as well, including inferior arcuate defects, inferior altitudinal, increased blind spot/nerve bundle defect generalized field constriction, and inferolateral defects[1,4]. Visual Evoked Potential (VEP) may also help detect and follow DON, and it may be more sensitive than kinetic perimetry $[1,40,41]$.

Orbital imaging techniques, particularly CT imaging, help to diagnosis and follow DON. Imaging gains particular importance in patients with bilateral disease as an afferent pupillary defect and color testing are less useful in this situation[21]. It is also important when other diagnostic tests do not clearly point to DON, as almost all patients with DON demonstrate CT imaging findings.

In addition to apical crowding, the overwhelming majority of $\mathrm{CT}$ imaging studies in cases of DON demonstrate moderate to severe muscle enlargement[1] (FIGURE 4A/4B). The muscle index represents a way to approximate the relative EOM volume within the orbit, and is significantly greater in orbits with DON than in orbits with TED alone[21]. The muscle index is calculated viewing a posterior coronal image of the orbit halfway between the orbital apex and the posterior globe. A horizontal line is drawn to transect the optic nerve, medial, and lateral rectus muscles. A vertical line is drawn to transect the optic nerve, superior, and inferior rectus muscles. The horizontal muscle index is calculated by the percentage of the orbital width that is occupied by the medial and lateral rectus muscles. The vertical muscle index is calculated by the percentage of orbital height that is occupied by the superior and inferior rectus muscles. A muscle index of greater than $70 \%$ is seen in about $2 / 3$ of cases of DON, and DON almost never occurs in the setting of a muscle index < $50 \%[21,23,28]$.

Orbital fat prolapse through the superior orbital fissure may predict DON, with up to $94 \%$ sensitivity, $91 \%$ specificity, a positive predict value of $69 \%$, and a negative predictive value of $98 \%$, however, a recent study found this feature in a lower percentage of cases of DON[22,23,47]. Enlargement of the superior ophthalmic vein may also predict DON[28]. An anteriorly displaced or enlarged lacrimal gland may also be seen in the setting of TED and possibly DON[48-50].

Magnetic resonance imaging (MRI) may reveal findings similar to CT imaging, but allows for superior soft tissue imaging[51-54]. T2-weighted and fat suppressed images using TIRM (Turbo-Inversion-Recovery-Magnitude) and STIR (Short-Tau Inversion Recovery) sequences enable detection of extraocular muscle/orbital fat interstitial edema and therefore disease activity. This makes MRI ideal for distinguishing active inflammatory TED from fibrotic end stage disease and is critical to the type and timing of treatment[51,55,56]. MRI 
changes of the optic nerve may correlate with clinical activity scores, suggesting that future MR imaging studies of the optic nerve itself may help detect DON[51,55,57-59]. Although MRI is superior at imaging soft tissue, CT is better at evaluating bony orbital anatomy, which is critical for surgical planning.

\section{Treatment overview}

As the majority of patients with TED develop only mild-moderate symptoms that improve spontaneously, supportive and conservative treatment generally suffices[60]. For patients with moderate-severe and active TED, therapy may reduce disease duration and severity. First line treatment generally consists of oral or intravenous (IV) glucocorticoids, and possibly orbital radiotherapy (ORT). Management of hyperthyroidism should be considered carefully, as dysthyroidism may precipitate disease progression and the treatment modality may affect the course of the disease, though this still remains unclear. Other immunosuppressive and biologic agents, such as methotrexate, rapamycin, adalimumab, and rituximab, have been investigated but are generally second line therapies. Rehabilitative surgery is best performed after cessation of active disease, but may be required earlier for cases of DON refractory to medical treatment.

There exists no consensus regarding the best treatment strategy for TED or DON. American Society of Ophthalmic and Reconstructive Surgery (ASOPRS) members chose both oral (43\% of members) and IV (49\% of members) steroids as first line treatments for severe TED. In contrast, European and Latin American physicians favor the use of IV over oral steroids as first line therapy[61]. ASOPRS members also use orbital decompression (83\%), ORT (70\%), biologic agents (33\%), and intraorbital steroid injections (28\%). Sightthreatening TED may involve a combination of these treatments.

\section{Corticosteroids}

Corticosteroids are the most widely used medical treatment for DON. Locally administered peribulbar steroids, such as triamcinolone acetonide may improve CAS with fewer side effects compared to oral glucocorticoids, but their effect on DON is less clear[62].

Pulsed IV glucocorticoids (iv-GC) treat TED more effectively than oral steroids, with fewer adverse effects [16]. However, iv-GC may rarely produce severe complications, including fatal acute liver failure, as well as cardiovascular and cerebrovascular events. The majority of severe complications are associated with doses exceeding 8 grams and daily or alternate day intravenous methylprednisolone (iv-MP)[63,64]. A recent EUGOGO consensus statement advocates iv-GC as a first line treatment for moderate-severe TED[16]. A generally accepted dosing regimen for these patients is a once-per-week dose of 500 milligrams iv-MP per week for 6 weeks, followed by 250 milligrams per week for another 6 weeks[65]. Cumulative dose should remain under approximately $6-8 \mathrm{~g}$, and patients should be continuously monitored during treatment.

DON may necessitate more aggressive measures, such as 500-1,000 milligrams iv-MP daily for 3 consecutive days, and repeated if necessary after 1 week $[64,66]$. Regimens such as this may lead to complete visual recovery in approximately $43 \%$ of cases. Other iv-MP regimens 
show similarly successful outcomes[67]. Some milder cases can be managed with oral steroids and careful monitoring. Because systemic glucocorticoids can effectively treat DON, they should be considered as a first line treatment in most cases.

\section{Radiation Therapy}

Many clinicians use ORT to treat moderate-to-severe TED. The most common dosing regimen calls for a cumulative dose of $20 \mathrm{~Gy}$ per eye, fractionated into ten doses over 10 days[68]. This regimen has proven very safe, and side effects are typically mild (periorbital edema, hair loss at entry ports, and conjunctival injection) and regress after treatment[69]. Severe side effects such as radiation retinopathy, optic neuropathy, and scleral necrosis are rare, and typically in the setting of prior chemotherapy treatment, diabetes mellitus, or systemic hypertension. Absolute contraindications for radiation therapy include severe hypertension and diabetic retinopathy, while diabetes mellitus without retinopathy is considered a relative contraindication. ORT should be avoided in patients under age 35 years[35,70]. (FIGURE 5) While existing data do not point to any clear and significant effect of ORT on the duration or severity of TED its role in treatment of DON are not well studied[71]. ORT does seem to play a preventative role in the development of DON, so it may also play a role in its treatment[72,73]. We typically use ORT in patients refractory to iv-MP who refuse surgery or who are poor surgical candidates.

\section{Alternative Immunosuppressive Agents}

A variety of steroid-sparing agents for TED and DON have been proposed and studied. Insights into new molecular pathways have exposed more specific targets for therapy. As Th-1 and macrophage type cytokines are implicated in the early stages of TED pathogenesis, agents targeting receptors for IL-1, IL-6, and TNF may be effective in treatment. These include anakinra, tocilizumab, lerdelimumab, infliximab, adalimumab, and etanercept[24]. Both TSHR and IGF-1R are potential targets for small molecule agents and monoclonal antibodies, such as M22 and teprotumumab[74,75]. Other options include modulation of costimulatory pathways and inhibition of T-cell migration and response through blockade of CXCR3 signaling with agents such as peroxisome proliferator-activated receptor (PPAR) $\gamma$ or a agonists, and CXCR3 antagonists[76].

Publications regarding the use of these agents for treatment of DON consist mostly of case reports, and small case series. Rapamycin was reported to improve symptoms, visual acuity, color plate testing, and visual fields in a case of DON refractory to steroids and maximal surgical decompression[77]. Adalimumab, an anti-TNF- $a$ monoclonal antibody, was found in one retrospective study to significantly improve inflammation in active TED, but only in patients with a high inflammatory index at baseline[78]. Tocilizumab, an anti-IL-6 monoclonal antibody, showed promising results in treatment of patients with corticosteroidresistant TED in a prospective interventional study[79]. Methotrexate improves CAS but may not completely treat DON[80]. Teprotumumab, an anti-IGF-1R monoclonal antibody, is currently under investigation in a clinical trial[81]. 
Rituximab, an anti-CD20 monoclonal antibody, may be of some benefit in treating TED and DON[82-84]. This agent may improve both visual acuity and CAS in cases of DON refractory to steroids and surgical decompression[83]. However, in patients with moderatesevere TED it may not significantly improve CAS as compared to placebo and may cause adverse events[85].

While further studies of rituximab and alternative immunosuppressive agents for DON seem warranted, newer agents in the future may prove more useful. When medical management of DON fails, efforts are directed at surgical decompression.

\section{Surgical Decompression}

Surgery for DON should decrease orbital soft tissue volume and/or expand its bony volume to decompress the optic nerve at the orbital apex. (FIGURE 6) Fat can be removed from any location within the orbit and the bony expansion can occur along any orbital wall. The inferomedial wall extends deeper into the orbital apex and generally represents the first-line approach to decompress the apex, although deep lateral wall bone removal and/or fat-only removal may also decompress the orbital apex. Several approaches to the medial wall have been described, including the transantral, transcutaneous, endonasal, and transcaruncular approaches.

\section{Transantral}

The transantral approach allows for removal of the inferior and medial orbital walls through a mucosal incision within the buccal sulcus, and removal of the anterior face of the maxilla. The technique can successfully treat DON, with improvement in visual acuity and visual field defects in approximately $91 \%$ of patients[86]. However, approximately $2 / 3$ of patients may develop new-onset diplopia after surgery. Other complications include lower eyelid entropion (9\%), alveolar branch trigeminal nerve hypoesthesia (5\%), and CSF leak (3.5\%) [86].

\section{Transcutaneous}

A lower eyelid subciliary incision, either with or without a swinging eyelid approach, yields excellent exposure of the inferomedial orbit for treatment of DON $[87,88]$. The swinging eyelid approach allows for greater visualization of the inferolateral orbital fat and lateral wall[87].

Although the Lynch approach is almost obsolete, a smaller incision $(1.5-2 \mathrm{~cm})$ transcutaneous medial approach yields adequate exposure and may result in less medial canthal webbing, telecanthus, iatrogenic diplopia, and damage to the lacrimal outflow system.[90,91].

\section{Orbital fat decompression}

Orbital fat can be removed during bony decompression or independently for treatment of DON. Transpalpebral extraconal and/or intraconal fat removal without bony decompression 
(but with iv-GC and/or ORT) successfully treated DON in 69 patients, though the specific outcomes regarding patients with DON were not reported[92]. In patients with DON having only modest EOM enlargement and more fat compartment enlargement, fat decompression alone may reverse DON in all cases with minimal complications[93].

\section{Endoscopic transnasal}

The inferomedial orbit may also be decompressed via a transnasal endoscopic approach. Described in 1990 by Kennedy et al, the endonasal approach effectively treats DON, but may induce new diplopia in 60-80\% of cases[94-96]. This may be due to the difficulty in maintaining an inferomedial bony strut via the endoscopic approach[95,97]. More recent attempts at selective posterior endoscopic decompression for DON may result in less postoperative diplopia[95]. Fat can also be removed during this approach to improve visual acuity and color vision with a low rate of consecutive diplopia[98].

\section{Transcaruncular}

The transcaruncular approach allows for quick, safe access to the orbital apex for removal of the medial and inferior walls $[43,89,99]$. It allows for more medial wall exposure than the transcutaneous approach, but it avoids adverse structural or functional consequences associated with a cutaneous incision. (FIGURE 7)

Several studies demonstrate significant improvement in all parameters of optic nerve function after transcaruncular approach decompression, allowing for rapid steroid taper[42,43,100,101]. This technique allows for a graded approach to removing the ethmoidal air cells and the inferior wall to preserve as much of the maxillo-ethmoidal strut as desired, lowering the risk of new-onset postoperative diplopia[43,89]. A meta-analysis of techniques for DON surgical decompression described the transcaruncular approach as easy and safe access to the orbital apex[99].

\section{Lateral Wall}

Lateral wall decompression can be performed through an upper eyelid or lateral canthal incision, and involves removal of the deep lateral orbital wall, typically with a high-speed drill or ultrasonic aspirator [102-105]. Lateral wall-only decompression can be performed with or without fat removal, and results in a low rate of new-onset postoperative diplopia[106]. The lateral wall does not extend as far posteriorly as the medial wall, but aggressive deep bony decompression with or without fat removal seems to decompress the orbital apex effectively for treatment of DON[107]. (FIGURE 8)

\section{Treatment Outcomes and Quality of Life}

Without treatment, DON may result in permanent vision loss[25]. Fortunately, regimens consisting of iv-MP, ORT, and surgical decompression effectively improve visual outcome in the vast majority of cases with complete visual recovery in approximately $70 \%$ of cases $[14,19]$. Positive predictive factors include younger age, shorter duration of neuropathy, and higher initial CAS, likely indicating earlier disease course[19]. Though quality of life (QoL) 
comprises an essential aspect of treatment outcome, it is far less commonly assessed and studied than clinical measures, especially for DON. Several studies have shown clinical measures to correlate poorly with QoL outcomes except in extreme cases, in which patients consistently report lower QoL scores[108].

\section{Expert Commentary}

Despite strong evidence to support the use of iv-GC as first-line treatment for moderatesevere TED, recent survey results indicate that a large proportion of physicians still favor oral steroids, especially in the United States. This may be due to the association of iv-GC with severe, possibly fatal adverse events. However, studies consistently show that iv-GC are better tolerated, more effective, and associated with less morbidity compared to oral steroids. Creating safe treatment practices based on the available data entails awareness of safe dosing regimens, screening patients based on risk factors such as cardiovascular disease and DM, and close monitoring of liver enzymes and cardiac function throughout treatment. Also, while corticosteroids often decrease disease activity, they rarely result in proptosis reduction and surgical decompression may still be warranted.

While ORT may prevent DON in some patients, its indiscriminate use for DON would result in treatment of many patients who would not benefit from the therapy. Therefore, given the current data, we reserve ORT for patients with refractory DON who do not elect, or are poor candidates for, surgical decompression. While a variety of approaches adequately decompress the orbital apex, we typically employ a transcaruncular approach, or occasionally a transnasal endoscopic approach.

\section{Five-year view}

As our understanding of the environmental, genetic, and immune factors underlying Graves' disease improves, future therapies will better target cellular and molecular mechanisms to prevent and treat DON. A promising animal model provides the opportunity to study the effects of novel drugs and treatments in vivo[109-111]. Pursuing studies that distinguish between the heterogeneous types of antibodies found in patients with DON will contribute greatly to understanding the pathophysiology of the disease, as well as provide more information on targets for treatment.

Reports of new treatment options for TED and DON are numerous, but data from controlled clinical trials are lacking. Well-designed clinical trials testing the efficacy of novel agents and surgical techniques will be essential in advancing and improving current treatment regimens and reducing disease mortality. This is especially true for treatments of DON, however, the rarity of this condition and the need for urgent treatment makes Level 1 data difficult to obtain. Efforts on the part of organizations such as EUGOGO and ITEDS will hopefully make possible organized multi-center randomized controlled trials, and provide valuable evidence-based data to enhance and refine techniques for managing both DON and TED. 


\title{
Acknowledgments
}

\author{
Funding
}

The authors declare the following funding NIH-NEI P30 Core Grant- IP30EY025585-01A1; Unrestricted Grant from Research to Prevent Blindness.

\section{References}

1. Neigel JM, Rootman J, Belkin RI, et al. Dysthyroid optic neuropathy. The crowded orbital apex syndrome. Ophthalmology. 1988; 95(11):1515-1521. [PubMed: 3211460]

2. Lazarus JH. Epidemiology of Graves' orbitopathy (GO) and relationship with thyroid disease. Best Pract Res Clin Endocrinol Metab. 2012; 26(3):273-279. [PubMed: 22632364]

3. Stan MN, Bahn RS. Risk factors for development or deterioration of Graves' ophthalmopathy. Thyroid. 2010; 20(7):777-783. [PubMed: 20578901]

4. Trobe JD, Glaser JS, Laflamme P. Dysthyroid optic neuropathy. Clinical profile and rationale for management. Arch Ophthalmol. 1978; 96(7):1199-1209. [PubMed: 666628]

5. Perros P, Crombie AL, Matthews JN, Kendall-Taylor P. Age and gender influence the severity of thyroid-associated ophthalmopathy: a study of 101 patients attending a combined thyroid-eye clinic. Clin Endocrinol (Oxf). 1993; 38(4):367-372. [PubMed: 8319368]

6. RUNDLE FF. Management of exophthalmos and related ocular changes in Graves' disease. Metabolism. 1957; 6(1):36-48. [PubMed: 13386967]

7. Douglas RS, Brix TH, Hwang CJ, Hegedus L, Smith TJ. Divergent frequencies of IGF-I receptorexpressing blood lymphocytes in monozygotic twin pairs discordant for Graves' disease: evidence for a phenotypic signature ascribable to nongenetic factors. J Clin Endocrinol Metab. 2009; 94(5): 1797-1802. [PubMed: 19240157]

8. Bartalena L, Pinchera A, Marcocci C. Management of Graves' ophthalmopathy: reality and perspectives. Endocr Rev. 2000; 21(2):168-199. [PubMed: 10782363]

9. Prummel MF, Wiersinga WM. Smoking and risk of Graves' disease. JAMA. 1993; 269(4):479-482. [PubMed: 8419666]

10. Wiersinga WM. Smoking and thyroid. Clin Endocrinol (Oxf). 2013; 79(2):145-151. [PubMed: 23581474]

11. Khong JJ, Finch S, De Silva C, et al. Risk Factors for Graves' Orbitopathy; the Australian ThyroidAssociated Orbitopathy Research (ATOR) Study. J Clin Endocrinol Metab. 2016; 101(7):27112720. [PubMed: 27055083]

12. Wiersinga WM. Management of Graves' ophthalmopathy. Nat Clin Pract Endocrinol Metab. 2007; 3(5):396-404. [PubMed: 17452966]

13. Lee JH, Lee SY, Yoon JS. Risk factors associated with the severity of thyroid-associated orbitopathy in Korean patients. Korean J Ophthalmol. 2010; 24(5):267-273. [PubMed: 21052505]

14. Jeon C, Shin JH, Woo KI, Kim YD. Clinical profile and visual outcomes after treatment in patients with dysthyroid optic neuropathy. Korean J Ophthalmol. 2012; 26(2):73-79. [PubMed: 22511831]

15. Kalmann R, Mourits MP. Diabetes mellitus: a risk factor in patients with Graves' orbitopathy. Br J Ophthalmol. 1999; 83(4):463-465. [PubMed: 10434871]

16. Bartalena L, Macchia PE, Marcocci C, Salvi M, Vermiglio F. Effects of treatment modalities for Graves' hyperthyroidism on Graves' orbitopathy: a 2015 Italian Society of Endocrinology Consensus Statement. J Endocrinol Invest. 2015; 38(4):481-487. [PubMed: 25722226]

17. Mensah A, Vignal-Clermont C, Mehanna C, et al. Dysthyroid optic neuropathy: atypical initial presentation and persistent visual loss. Orbit. 2009; 28(6):354-362. [PubMed: 19929659]

18. Kendler DL, Lippa J, Rootman J. The initial clinical characteristics of Graves' orbitopathy vary with age and sex. Arch Ophthalmol. 1993; 111(2):197-201. [PubMed: 8431156]

19. Miskiewicz P, Rutkowska B, Jablonska A, et al. Complete recovery of visual acuity as the main goal of treatment in patients with dysthyroid optic neuropathy. Endokrynol Pol. 2016; 67(2):166173. [PubMed: 26884288] 
20. Feldon SE, Muramatsu S, Weiner JM. Clinical classification of Graves' ophthalmopathy. Identification of risk factors for optic neuropathy. Arch Ophthalmol. 1984; 102(10):1469-1472. [PubMed: 6548373]

21. Barrett L, Glatt HJ, Burde RM, Gado MH. Optic nerve dysfunction in thyroid eye disease: CT. Radiology. 1988; 167(2):503-507. [PubMed: 3357962]

22. McKeag D, Lane C, Lazarus JH, et al. Clinical features of dysthyroid optic neuropathy: a European Group on Graves' Orbitopathy (EUGOGO) survey. Br J Ophthalmol. 2007; 91(4):455-458. [PubMed: 17035276]

23. Giaconi JA, Kazim M, Rho T, Pfaff C. CT scan evidence of dysthyroid optic neuropathy. Ophthal Plast Reconstr Surg. 2002; 18(3):177-182.

24. Bahn RS. Current Insights into the Pathogenesis of Graves' Ophthalmopathy. Horm Metab Res. 2015; 47(10):773-778. [PubMed: 26361262]

25. Victores AJ, Takashima M. Thyroid Eye Disease: Optic Neuropathy and Orbital Decompression. Int Ophthalmol Clin. 2016; 56(1):69-79. [PubMed: 26626933]

26. Weis E, Heran MK, Jhamb A, et al. Quantitative computed tomographic predictors of compressive optic neuropathy in patients with thyroid orbitopathy: a volumetric analysis. Ophthalmology. 2012; 119(10):2174-2178. [PubMed: 22709420]

27. Enzmann D, Marshal WH Jr, Rosenthal AR, Kriss JP. Computed tomography in Graves' ophthalmopathy. Radiology. 1976; 118(3):615-620. [PubMed: 946330]

28. da Lima BR, Perry JD. Superior ophthalmic vein enlargement and increased muscle index in dysthyroid optic neuropathy. Ophthal Plast Reconstr Surg. 2013; 29(3):147-149.

29. Otto AJ, Koornneef L, Mourits MP, Deen-van Leeuwen L. Retrobulbar pressures measured during surgical decompression of the orbit. Br J Ophthalmol. 1996; 80(12):1042-1045. [PubMed: 9059266]

30. Iyer S, Bahn R. Immunopathogenesis of Graves' ophthalmopathy: the role of the TSH receptor. Best Pract Res Clin Endocrinol Metab. 2012; 26(3):281-289. [PubMed: 22632365]

31. Walasik-Szemplinska D, Pauk-Domanska M, Sanocka U, Sudol-Szopinska I. Doppler imaging of orbital vessels in the assessment of the activity and severity of thyroid-associated orbitopathy. J Ultrason. 2015; 15(63):388-397. [PubMed: 26807296]

32. Anderson RL, Tweeten JP, Patrinely JR, Garland PE, Thiese SM. Dysthyroid optic neuropathy without extraocular muscle involvement. Ophthalmic Surg. 1989; 20(8):568-574. [PubMed: 2779967]

33. Mourits MP, Prummel MF, Wiersinga WM, Koornneef L. Clinical activity score as a guide in the management of patients with Graves' ophthalmopathy. Clin Endocrinol (Oxf). 1997; 47(1):9-14. [PubMed: 9302365]

34. Dolman PJ, Rootman J. VISA Classification for Graves orbitopathy. Ophthal Plast Reconstr Surg. 2006; 22(5):319-324.

35. Bartalena L, Baldeschi L, Dickinson A, et al. Consensus statement of the European Group on Graves' orbitopathy (EUGOGO) on management of GO. Eur J Endocrinol. 2008; 158(3):273-285. [PubMed: 18299459]

36. Werner SC. Modification of the classification of the eye changes of Graves' disease. Am J Ophthalmol. 1977; 83(5):725-727. [PubMed: 577380]

37. Kuriyan AE, Woeller CF, O'Loughlin CW, Phipps RP, Feldon SE. Orbital fibroblasts from thyroid eye disease patients differ in proliferative and adipogenic responses depending on disease subtype. Invest Ophthalmol Vis Sci. 2013; 54(12):7370-7377. [PubMed: 24135759]

38. Regensburg NI, Wiersinga WM, Berendschot TT, Potgieser P, Mourits MP. Do subtypes of graves' orbitopathy exist? Ophthalmology. 2011; 118(1):191-196. [PubMed: 20673587]

39. Beden U, Kaya S, Yeter V, Erkan D. Contrast sensitivity of thyroid associated ophthalmopathy patients without obvious optic neuropathy. ScientificWorldJournal. 2013; 2013:943789. [PubMed: 24453927]

40. Lipski A, Eckstein A, Esser J, et al. Course of pattern-reversed visual evoked cortical potentials in 30 eyes after bony orbital decompression in dysthyroid optic neuropathy. Br J Ophthalmol. 2011; 95(2):222-226. [PubMed: 20584712] 
41. Tsaloumas MD, Good PA, Burdon MA, Misson GP. Flash and pattern visual evoked potentials in the diagnosis and monitoring of dysthyroid optic neuropathy. Eye (Lond). 1994; 8(Pt 6):638-645. [PubMed: 7867819]

42. McCann JD, Goldberg RA, Anderson RL, Burroughs JR, Ben Simon GJ. Medial wall decompression for optic neuropathy but lateral wall decompression with fat removal for non vision-threatening indications. Am J Ophthalmol. 2006; 141(5):916-917. [PubMed: 16678507]

43. Perry JD, Kadakia A, Foster JA. Transcaruncular orbital decompression for dysthyroid optic neuropathy. Ophthal Plast Reconstr Surg. 2003; 19(5):353-358.

44. Mourits MP, Suttorp-Schulten MS, Tijssen RO, Apkarian P. Contrast sensitivity and the diagnosis dysthyroid optic neuropathy. Doc Ophthalmol. 1990; 74(4):329-335. [PubMed: 2257776]

45. Mourits MP, Koornneef L, Wiersinga WM, Prummel MF, Berghout A, van der Gaag R. Orbital decompression for Graves' ophthalmopathy by inferomedial, by inferomedial plus lateral, and by coronal approach. Ophthalmology. 1990; 97(5):636-641. [PubMed: 2342809]

46. Suttorp-Schulten MS, Tijssen R, Mourits MP, Apkarian P. Contrast sensitivity function in Graves' ophthalmopathy and dysthyroid optic neuropathy. Br J Ophthalmol. 1993; 77(11):709-712. [PubMed: 8280684]

47. Birchall D, Goodall KL, Noble JL, Jackson A. Graves ophthalmopathy: intracranial fat prolapse on CT images as an indicator of optic nerve compression. Radiology. 1996; 200(1):123-127. [PubMed: 8657899]

48. Nugent RA, Belkin RI, Neigel JM, et al. Graves orbitopathy: correlation of CT and clinical findings. Radiology. 1990; 177(3):675-682. [PubMed: 2243967]

49. Harris MA, Realini T, Hogg JP, Sivak-Callcott JA. CT dimensions of the lacrimal gland in Graves orbitopathy. Ophthal Plast Reconstr Surg. 2012; 28(1):69-72.

50. Bingham CM, Harris MA, Realini T, Nguyen J, Hogg JP, Sivak-Callcott JA. Calculated computed tomography volumes of lacrimal glands and comparison to clinical findings in patients with thyroid eye disease. Ophthal Plast Reconstr Surg. 2014; 30(2):116-118.

51. Kirsch E, von Arx G, Hammer B. Imaging in Graves' orbitopathy. Orbit. 2009; 28(4):219-225. [PubMed: 19839878]

52. Goncalves AC, Gebrim EM, Monteiro ML. Imaging studies for diagnosing Graves' orbitopathy and dysthyroid optic neuropathy. Clinics (Sao Paulo). 2012; 67(11):1327-1334. [PubMed: 23184212]

53. Hu H, Xu XQ, Wu FY, et al. Diagnosis and stage of Graves' ophthalmopathy: Efficacy of quantitative measurements of the lacrimal gland based on 3-T magnetic resonance imaging. Exp Ther Med. 2016; 12(2):725-729. [PubMed: 27446267]

54. Kahaly GJ. Imaging in thyroid-associated orbitopathy. Eur J Endocrinol. 2001; 145(2):107-118. [PubMed: 11454505]

55. Mayer EJ, Fox DL, Herdman G, et al. Signal intensity, clinical activity and cross-sectional areas on MRI scans in thyroid eye disease. Eur J Radiol. 2005; 56(1):20-24. [PubMed: 15896938]

56. Yokoyama N, Nagataki S, Uetani M, Ashizawa K, Eguchi K. Role of magnetic resonance imaging in the assessment of disease activity in thyroid-associated ophthalmopathy. Thyroid. 2002; 12(3): 223-227. [PubMed: 11952043]

57. Kirsch EC, Kaim AH, De Oliveira MG, von Arx G. Correlation of signal intensity ratio on orbital MRI-TIRM and clinical activity score as a possible predictor of therapy response in Graves' orbitopathy--a pilot study at 1.5 T. Neuroradiology. 2010; 52(2):91-97. [PubMed: 19756565]

58. Tachibana S, Murakami T, Noguchi H, et al. Orbital magnetic resonance imaging combined with clinical activity score can improve the sensitivity of detection of disease activity and prediction of response to immunosuppressive therapy for Graves' ophthalmopathy. Endocr J. 2010; 57(10):853861. [PubMed: 20733265]

59. Ozkan B, Anik Y, Katre B, Altintas O, Gencturk M, Yuksel N. Quantitative Assessment of Optic Nerve With Diffusion Tensor Imaging in Patients With Thyroid Orbitopathy. Ophthal Plast Reconstr Surg. 2015; 31(5):391-395.

60. Gillespie EF, Smith TJ, Douglas RS. Thyroid eye disease: towards an evidence base for treatment in the 21st century. Curr Neurol Neurosci Rep. 2012; 12(3):318-324. [PubMed: 22354545] 
61. Perumal B, Meyer DR. Treatment of severe thyroid eye disease: a survey of the American Society of Ophthalmic Plastic and Reconstructive Surgery (ASOPRS). Ophthal Plast Reconstr Surg. 2015; 31(2):127-131.

62. Alkawas AA, Hussein AM, Shahien EA. Orbital steroid injection versus oral steroid therapy in management of thyroid-related ophthalmopathy. Clin Experiment Ophthalmol. 2010; 38(7):692697. [PubMed: 20497432]

63. Le Moli R, Baldeschi L, Saeed P, Regensburg N, Mourits MP, Wiersinga WM. Determinants of liver damage associated with intravenous methylprednisolone pulse therapy in Graves' ophthalmopathy. Thyroid. 2007; 17(4):357-362. [PubMed: 17465867]

64. Marcocci C, Watt T, Altea MA, et al. Fatal and non-fatal adverse events of glucocorticoid therapy for Graves' orbitopathy: a questionnaire survey among members of the European Thyroid Association. Eur J Endocrinol. 2012; 166(2):247-253. [PubMed: 22058081]

65. Bhatti MT, Dutton JJ. Thyroid eye disease: therapy in the active phase. J Neuroophthalmol. 2014; 34(2):186-197. [PubMed: 24821102]

66. Eckstein A, Schittkowski M, Esser J. Surgical treatment of Graves' ophthalmopathy. Best Pract Res Clin Endocrinol Metab. 2012; 26(3):339-358. [PubMed: 22632370]

67. Wakelkamp IM, Baldeschi L, Saeed P, Mourits MP, Prummel MF, Wiersinga WM. Surgical or medical decompression as a first-line treatment of optic neuropathy in Graves' ophthalmopathy? A randomized controlled trial. Clin Endocrinol (Oxf). 2005; 63(3):323-328. [PubMed: 16117821]

68. Donaldson SS, Bagshaw MA, Kriss JP. Supervoltage orbital radiotherapy for Graves' ophthalmopathy. J Clin Endocrinol Metab. 1973; 37(2):276-285. [PubMed: 4198257]

69. Chundury RV, Weber AC, Perry JD. Orbital Radiation Therapy in Thyroid Eye Disease. Ophthal Plast Reconstr Surg. 2016; 32(2):83-89.

70. Tanda ML, Bartalena L. Efficacy and safety of orbital radiotherapy for graves' orbitopathy. J Clin Endocrinol Metab. 2012; 97(11):3857-3865. [PubMed: 22962421]

71. Perry JD, Feldon SE. Rationale for radiotherapy in thyroid eye disease. Am J Ophthalmol. 2009; 148(6):818-819. [PubMed: 19932802]

72. Kim JW, Han SH, Son BJ, Rim TH, Keum KC, Yoon JS. Efficacy of combined orbital radiation and systemic steroids in the management of Graves' orbitopathy. Graefes Arch Clin Exp Ophthalmol. 2016; 254(5):991-998. [PubMed: 26876240]

73. Shams PN, Ma R, Pickles T, Rootman J, Dolman PJ. Reduced risk of compressive optic neuropathy using orbital radiotherapy in patients with active thyroid eye disease. Am J Ophthalmol. 2014; 157(6):1299-1305. [PubMed: 24582992]

74. Turcu AF, Kumar S, Neumann S, et al. A small molecule antagonist inhibits thyrotropin receptor antibody-induced orbital fibroblast functions involved in the pathogenesis of Graves ophthalmopathy. J Clin Endocrinol Metab. 2013; 98(5):2153-2159. [PubMed: 23482611]

75. Chen H, Mester T, Raychaudhuri N, et al. Teprotumumab, an IGF-1R blocking monoclonal antibody inhibits TSH and IGF-1 action in fibrocytes. J Clin Endocrinol Metab. 2014; 99(9):E1635-40. [PubMed: 24878056]

76. Fallahi P, Ferrari SM, Elia G, et al. Novel Therapies for Thyroid Autoimmune Diseases. Expert Rev Clin Pharmacol. 2016; 9(6):853-861. [PubMed: 26900630]

77. Chang S, Perry JD, Kosmorsky GS, Braun WE. Rapamycin for treatment of refractory dysthyroid compressive optic neuropathy. Ophthal Plast Reconstr Surg. 2007; 23(3):225-226.

78. Ayabe R, Rootman DB, Hwang CJ, Ben-Artzi A, Goldberg R. Adalimumab as steroid-sparing treatment of inflammatory-stage thyroid eye disease. Ophthal Plast Reconstr Surg. 2014; 30(5): 415-419.

79. Perez-Moreiras JV, Alvarez-Lopez A, Gomez EC. Treatment of active corticosteroid-resistant graves' orbitopathy. Ophthal Plast Reconstr Surg. 2014; 30(2):162-167.

80. Strianese D, Iuliano A, Ferrara M, et al. Methotrexate for the treatment of thyroid eye disease. J Ophthalmol. 2014; 2014:128903. [PubMed: 24678411]

81. Khong JJ, McNab AA, Ebeling PR, Craig JE, Selva D. Pathogenesis of thyroid eye disease: review and update on molecular mechanisms. Br J Ophthalmol. 2016; 100(1):142-150. [PubMed: 26567024] 
82. Salvi M, Vannucchi G, Campi I, et al. Rituximab treatment in a patient with severe thyroidassociated ophthalmopathy: effects on orbital lymphocytic infiltrates. Clin Immunol. 2009; 131(2): 360-365. [PubMed: 19195932]

83. Khanna D, Chong KK, Afifiyan NF, et al. Rituximab treatment of patients with severe, corticosteroid-resistant thyroid-associated ophthalmopathy. Ophthalmology. 2010; 117(1):133139.e2. [PubMed: 19818507]

84. Salvi M, Vannucchi G, Campi I, et al. Treatment of Graves' disease and associated ophthalmopathy with the anti-CD20 monoclonal antibody rituximab: an open study. Eur J Endocrinol. 2007; 156(1):33-40. [PubMed: 17218723]

85. Stan MN, Garrity JA, Carranza Leon BG, Prabin T, Bradley EA, Bahn RS. Randomized controlled trial of rituximab in patients with Graves' orbitopathy. J Clin Endocrinol Metab. 2015; 100(2): 432-441. [PubMed: 25343233]

86. Garrity JA, Fatourechi V, Bergstralh EJ, et al. Results of transantral orbital decompression in 428 patients with severe Graves' ophthalmopathy. Am J Ophthalmol. 1993; 116(5):533-547. [PubMed: 8238212]

87. McCord CD Jr. Orbital decompression for Graves' disease. Exposure through lateral canthal and inferior fornix incision. Ophthalmology. 1981; 88(6):533-541. [PubMed: 6894974]

88. Leone CR Jr, Bajandas FJ. Inferior orbital decompression for dysthyroid optic neuropathy. Ophthalmology. 1981; 88(6):525-532. [PubMed: 7267026]

89. Shorr N, Baylis HI, Goldberg RA, Perry JD. Transcaruncular approach to the medial orbit and orbital apex. Ophthalmology. 2000; 107(8):1459-1463. [PubMed: 10919889]

90. Nunery WR, Nunery CW, Martin RT, Truong TV, Osborn DR. The risk of diplopia following orbital floor and medial wall decompression in subtypes of ophthalmic Graves' disease. Ophthal Plast Reconstr Surg. 1997; 13(3):153-160.

91. Timoney PJ, Sokol JA, Hauck MJ, Lee HB, Nunery WR. Transcutaneous medial canthal tendon incision to the medial orbit. Ophthal Plast Reconstr Surg. 2012; 28(2):140-144.

92. Richter DF, Stoff A, Olivari N. Transpalpebral decompression of endocrine ophthalmopathy by intraorbital fat removal (Olivari technique): experience and progression after more than 3000 operations over 20 years. Plast Reconstr Surg. 2007; 120(1):109-123. [PubMed: 17572552]

93. Kazim M, Trokel SL, Acaroglu G, Elliott A. Reversal of dysthyroid optic neuropathy following orbital fat decompression. Br J Ophthalmol. 2000; 84(6):600-605. [PubMed: 10837384]

94. Kennedy DW, Goodstein ML, Miller NR, Zinreich SJ. Endoscopic transnasal orbital decompression. Arch Otolaryngol Head Neck Surg. 1990; 116(3):275-282. [PubMed: 2306344]

95. Chu EA, Miller NR, Lane AP. Selective endoscopic decompression of the orbital apex for dysthyroid optic neuropathy. Laryngoscope. 2009; 119(6):1236-1240. [PubMed: 19418538]

96. Roberts CJ, Murphy MF, Adams GG, Lund VJ. Strabismus following endoscopic orbital decompression for thyroid eye disease. Strabismus. 2003; 11(3):163-171. [PubMed: 14710474]

97. Goldberg RA, Shorr N, Cohen MS. The medical orbital strut in the prevention of postdecompression dystopia in dysthyroid ophthalmopathy. Ophthal Plast Reconstr Surg. 1992; 8(1):32-34.

98. Lv Z, Selva D, Yan W, Daniel P, Tu Y, Wu W. Endoscopical Orbital Fat Decompression with Medial Orbital Wall Decompression for Dysthyroid Optic Neuropathy. Curr Eye Res. 2016; 41(2): 150-158. [PubMed: 25835075]

99. Boboridis KG, Uddin J, Mikropoulos DG, et al. Critical Appraisal on Orbital Decompression for Thyroid Eye Disease: A Systematic Review and Literature Search. Adv Ther. 2015; 32(7):595611. [PubMed: 26202828]

100. Chang EL, Bernardino CR, Rubin PA. Transcaruncular orbital decompression for management of compressive optic neuropathy in thyroid-related orbitopathy. Plast Reconstr Surg. 2003; 112(3): 739-747. [PubMed: 12960854]

101. Liao SL, Chang TC, Lin LL. Transcaruncular orbital decompression: an alternate procedure for Graves ophthalmopathy with compressive optic neuropathy. Am J Ophthalmol. 2006; 141(5): 810-818. [PubMed: 16527228] 
102. Cho RI, Choe CH, Elner VM. Ultrasonic bone removal versus high-speed burring for lateral orbital decompression: comparison of surgical outcomes for the treatment of thyroid eye disease. Ophthal Plast Reconstr Surg. 2010; 26(2):83-87.

103. Vrcek I, Starks V, Mancini R, Gilliland G. Use of an ultrasonic bone curette (Sonopet) in orbital and oculoplastic surgery. Proc (Bayl Univ Med Cent). 2015; 28(1):91-93. [PubMed: 25552814]

104. Sivak-Callcott JA, Linberg JV, Patel S. Ultrasonic bone removal with the Sonopet Omni: a new instrument for orbital and lacrimal surgery. Arch Ophthalmol. 2005; 123(11):1595-1597. [PubMed: 16286624]

105. Goldberg RA, Hwang MM, Garbutt MV, Shorr N. Orbital decompression for non-Graves' orbitopathy: a consideration of extended indications for decompression. Ophthal Plast Reconstr Surg. 1995; 11(4):245-52. discussion 253.

106. Goldberg RA, Perry JD, Hortaleza V, Tong JT. Strabismus after balanced medial plus lateral wall versus lateral wall only orbital decompression for dysthyroid orbitopathy. Ophthal Plast Reconstr Surg. 2000; 16(4):271-277.

107. Choe $\mathrm{CH}$, Cho RI, Elner VM. Comparison of lateral and medial orbital decompression for the treatment of compressive optic neuropathy in thyroid eye disease. Ophthal Plast Reconstr Surg. 2011; 27(1):4-11.

108. Du Y, Ye H, Li K, et al. Vision-related quality of life tends to be more severely impaired in patients with dysthyroid optic neuropathy. Curr Eye Res. 2014; 39(5):532-536. [PubMed: 24215175]

109. Zhao SX, Tsui S, Cheung A, Douglas RS, Smith TJ, Banga JP. Orbital fibrosis in a mouse model of Graves' disease induced by genetic immunization of thyrotropin receptor cDNA. J Endocrinol. 2011; 210(3):369-377. [PubMed: 21715431]

110. Moshkelgosha S, So PW, Deasy N, Diaz-Cano S, Banga JP. Cutting edge: retrobulbar inflammation, adipogenesis, and acute orbital congestion in a preclinical female mouse model of Graves' orbitopathy induced by thyrotropin receptor plasmid-in vivo electroporation. Endocrinology. 2013; 154(9):3008-3015. [PubMed: 23900776]

111. Nagayama Y, Nakahara M, Abiru N. Animal models of Graves' disease and Graves' orbitopathy. Curr Opin Endocrinol Diabetes Obes. 2015; 22(5):381-386. [PubMed: 26181432] 


\section{Key Issues}

- Dysthyroid Optic Neuropathy (DON) can cause permanent vision loss and results from an orbital apex syndrome.

- In addition to thyroid dysfunction, male gender and older age are strong risk factors for development of DON while the role of tobacco status is less defined.

- Careful clinical evaluation for DON is critical and visual acuity, color vision, pupillary exam, contrast sensitivity, visual field testing, and visual evoked potential can aid in diagnosis and tracking progression.

- DON management involves obtaining a euthyroid state, protecting the ocular surface, and orbital decompression via medical or surgical means.

- Medical management of DON involves corticosteroids and some centers also employ orbital radiotherapy and/or immunosuppressive agents

- Surgical orbital decompression is often necessary for DON refractory to medical management.

- $\quad$ Prompt treatment in DON can result in stabilization and improvement in vision.

- $\quad$ Further studies, including randomized controlled clinical trials are necessary to better elucidate the role of novel agents and surgical techniques to better optimize DON management. 


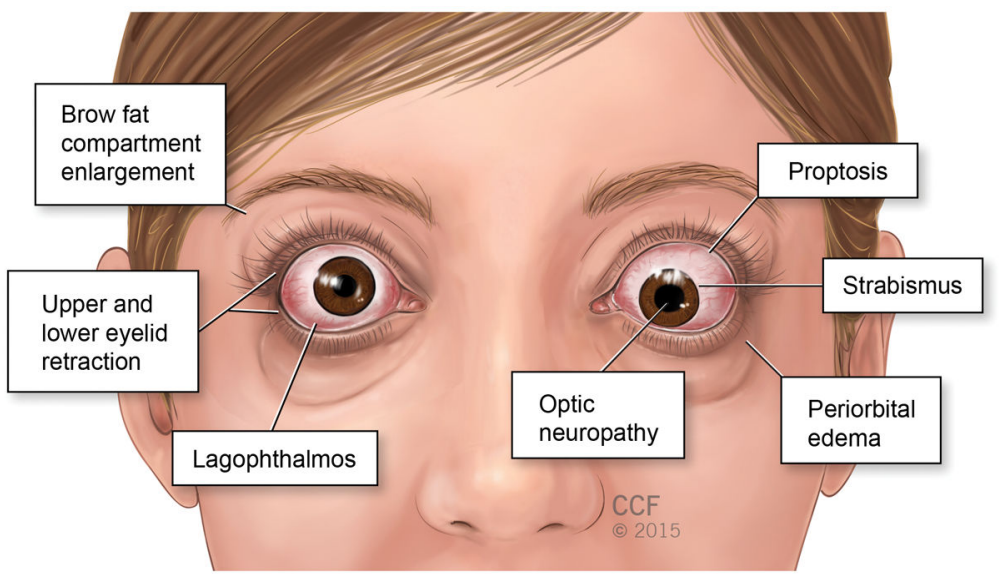

Figure 1.

Thyroid eye disease illustration. Various clinical manifestations found in moderate to severe thyroid eye disease are shown in this illustration

Original figure with Cleveland Clinic Foundation copyright 2015 


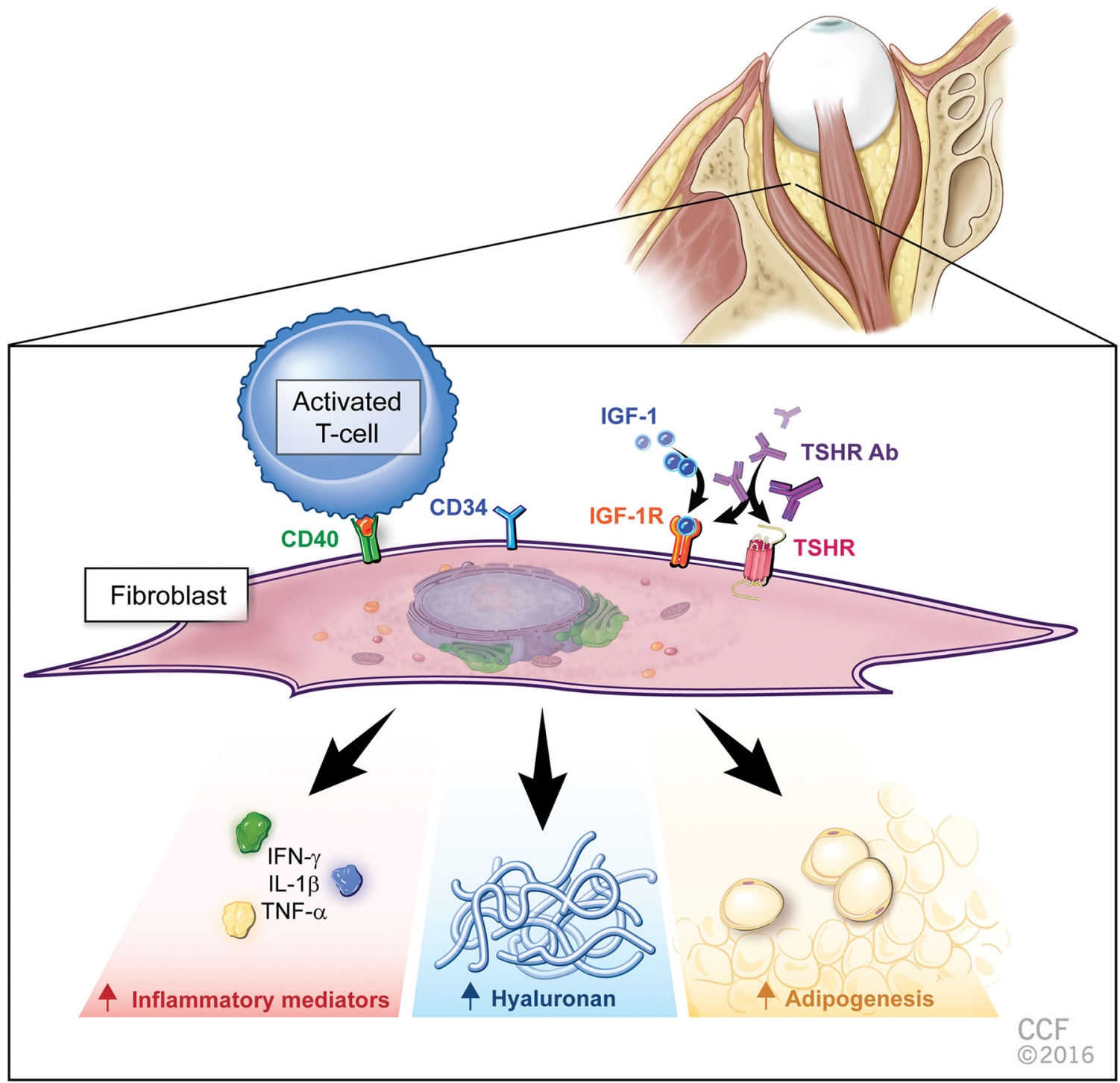

Figure 2.

Orbital Fibroblast role in Thyroid Eye Disease

Original figure with Cleveland Clinic Foundation copyright 2016 


Examination/Test:
Visual Acuity
Pupillary Exam
Color Vision
Contrast Sensitivity
Visual Field Testing
Visual Evoked Potential

Classic Finding

Often $<20 / 40$, but may be later finding

May have relative APD if unilateral or asymmetric

Often decreased

Often decreased

Central/Paracentral Scotoma with peripheral break out patterns

Often decreased $\mathrm{P} 2 / \mathrm{P} 100$ amplitude and increased P100 latency

Figure 3.

Clinical Evaluation of Optic Nerve Function in DON 


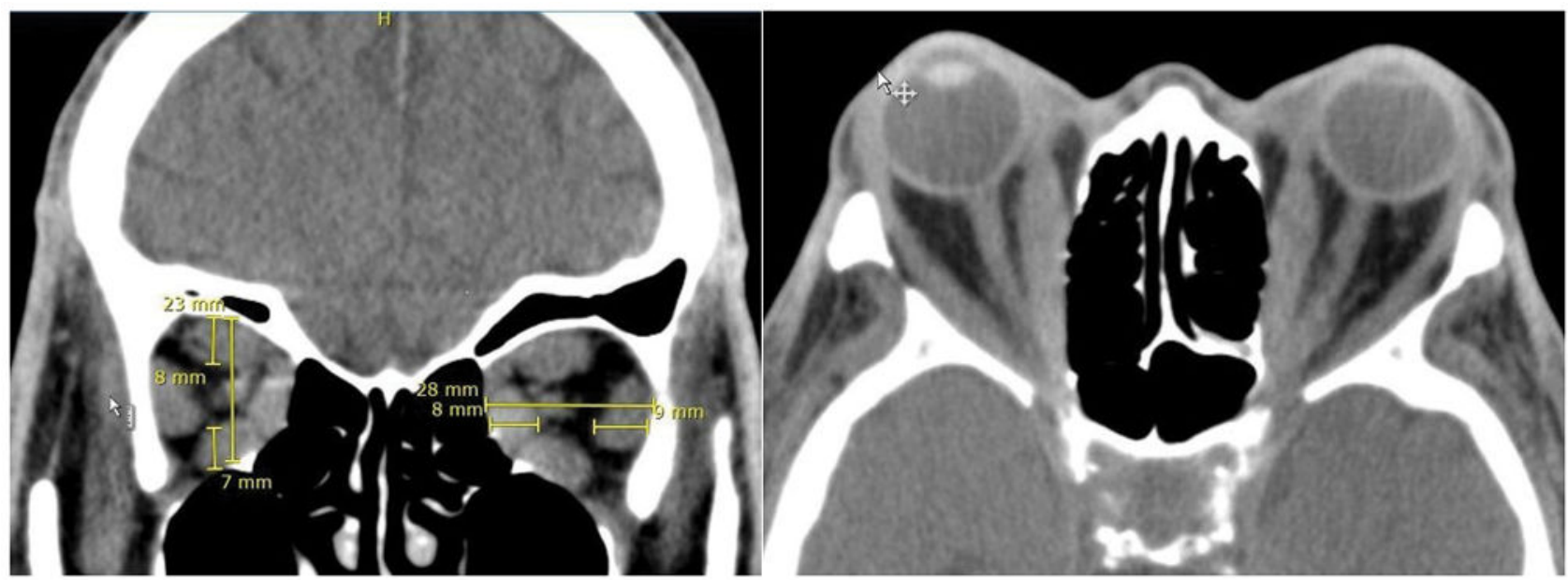

FIG. 4.

A. Muscle Index measurement. B. Apical Crowding.

Original figure with Cleveland Clinic Foundation copyright 2016 


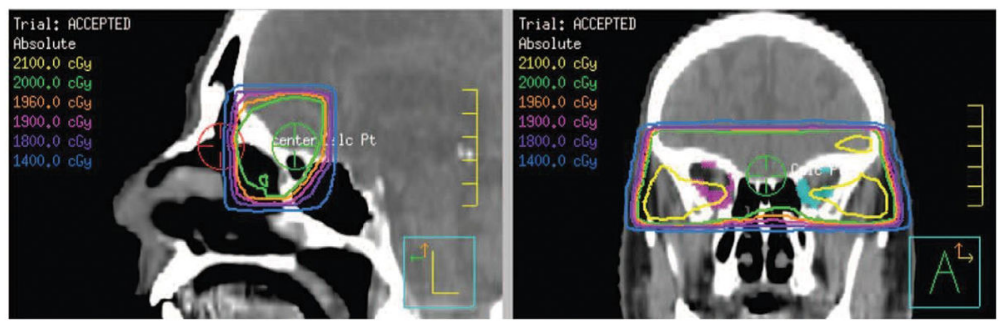

Figure 5.

ORT isodose plan. Pretreatment evaluation involves isodose planning which can target Xrays to specific anatomic locations. In this plan, the extraocular muscles are targeted along with orbital fat with attempt to minimize radiation to other important ocular structures. ORT, orbital radiation therapy.

Permission obtained for re-print from Chundury et al, Opthalmic Plastic and Reconstructive Surgery, 2015.

(Permission license present in previously uploaded files) 


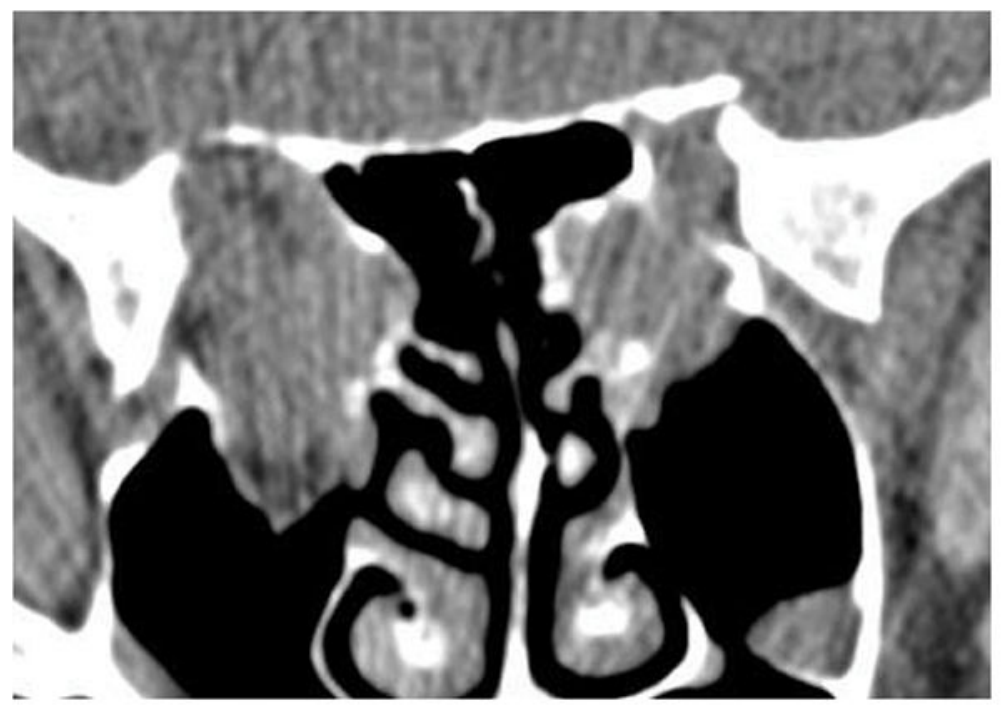

Figure 6.

Coronal CT scan post-orbital decompression for DON.

Original figure with Cleveland Clinic Foundation copyright 2016 


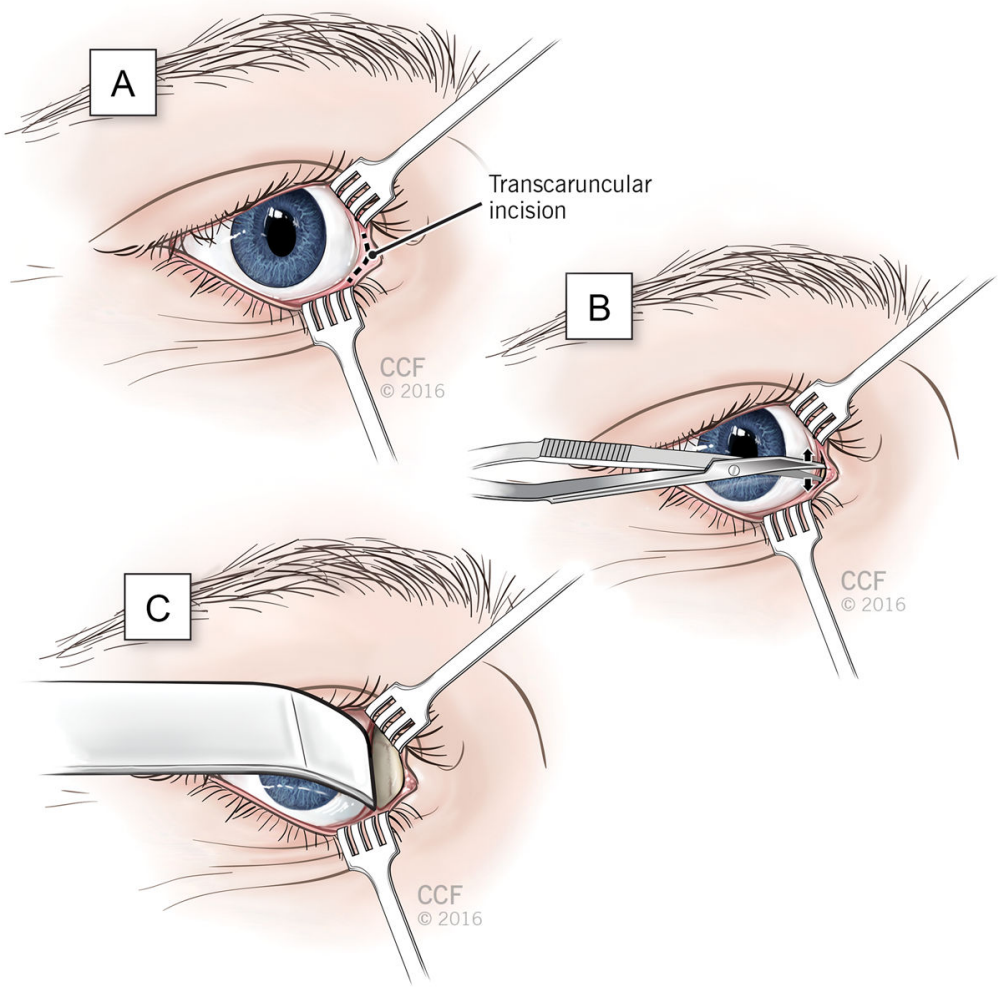

Figure 7.

Transcaruncular approach to medial orbit

Original figure with Cleveland Clinic Foundation copyright 2016 


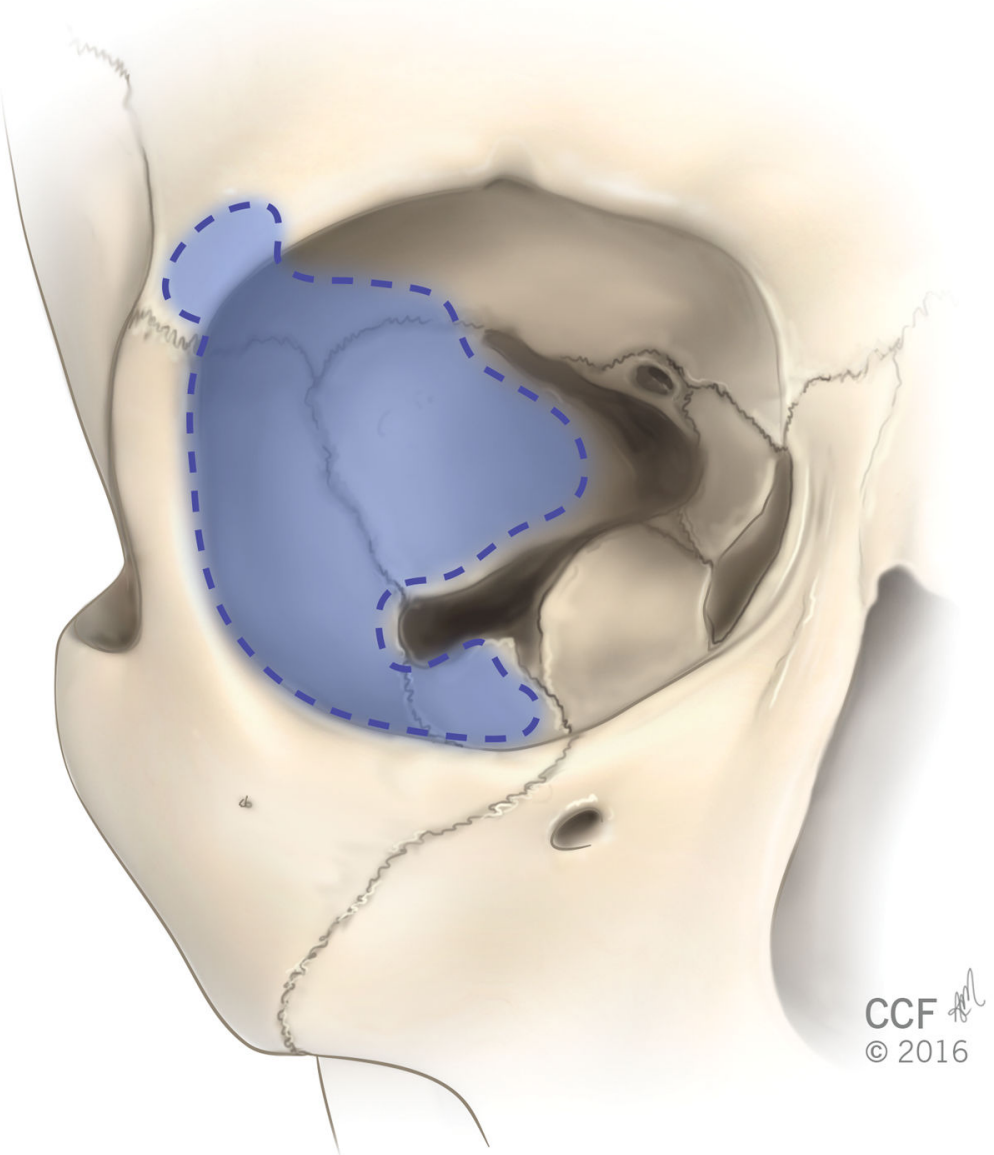

Figure 8.

Lateral orbital decompression for DON

Original figure with Cleveland Clinic Foundation copyright 2016 


\section{Table 1}

Clinical Activity Score (CAS). Presence of each symptom/sign receives 1 point. A sum score greater than 3/7 at first exam or greater than $4 / 10$ in subsequent examinations defines active ophthalmopathy (altered after Mourits et al original description)

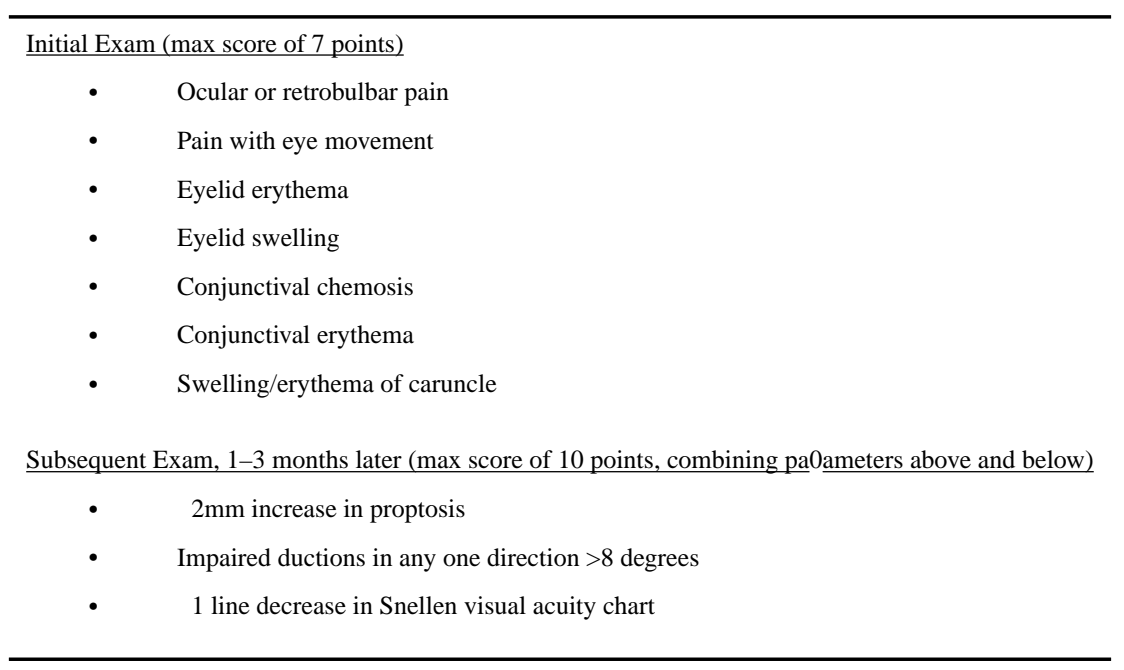




\section{Table 2}

VISA Inflammatory Score. Presence of each sign/symptom receives 1-2 points (max score of 10). Patients with sum scores $<4 / 10$ are managed conservatively while patients with scores $>5 / 10$ or with evidence of inflammatory progression are more aggressively treated (altered after Dolman and Rootman original description).

-
-
-
-
-
Exwelling of caruncle (1 point)
Eyelid erythema (1 point)
festoon ( 2 points $)$
Retrobulbar pain at rest (1 point)
Retrobulbar pain with eye movement (1 point)
Diurnal variation (1 point)

